\title{
Label-Free Impedimetric Immunosensors for Detection of Snake Venoms Using Polyaniline as a Transducer Substrate
}

\author{
Ricardo Adriano Dorledo de Faria*1, Pedro Henrique Cabral de Souza ${ }^{1}$, Vanessa de Freitas Cunha Lins ${ }^{1}$, \\ Tulio Matencio ${ }^{1,2}$ and Luiz Guilherme Dias Heneine ${ }^{3}$ \\ ${ }^{1}$ Department of Chemical Engineering, Universidade Federal de Minas Gerais (UFMG), Brazil \\ ${ }^{2}$ Department of Chemistry, Universidade Federal de Minas Gerais (UFMG), Brazil
}

${ }^{3}$ Laboratory of Applied Immunology, Fundação Ezequiel Dias (FUNED), Brazil

*Corresponding author: Ricardo Adriano Dorledo de Faria, Department of Chemical Engineering, Universidade Federal de Minas Gerais (UFMG), Belo Horizonte, Minas Gerais 30270-901, Brazil

\begin{abstract}
ARTICLE INFO
Received: 蔧 January 27, 2020

Published: 慧 February 06, 2020

Citation: Ricardo Adriano Dorledo de Faria, Pedro Henrique Cabral de Souza, Vanessa de Freitas Cunha Lins, Tulio Matencio, Luiz Guilherme Dias Heneine. Label-Free Impedimetric Immunosensors for Detection of Snake Venoms Using Polyaniline as a Transducer Substrate. Biomed J Sci \& Tech Res 25(3)-2020. BJSTR. MS.ID.004190.

ABSTRACT

Two label-free impedimetric immunosensors were developed to be employed in the specific diagnosis of snakebite. To produce the devices, a conductive substrate was obtained by electrodeposition of Polyaniline on the surface of a Crofer 22 APU steel. The polymer-based substrates were functionalized either with an affinity purified antibody specific for venom of the Bothrops genus or for the Crotalus genus. The performance of the as-prepared sensors was evaluated by exposing them to different concentrations of the venoms from Bothrops, Crotalus and Micrurus snakes. The capacity to recognize the specific analytes was measure by Electrochemical Impedance Spectroscopy within a frequency range from $10,000 \mathrm{~Hz}$ to $0.01 \mathrm{~Hz}$. The increase of the immunosensors' charge transfer resistance was correlated to the increase in the concentration of the homologous venoms pool with a detection limit of $0.1 \mu \mathrm{g}$. $\mathrm{m} \mathrm{L}^{-1}$. Heterologous venoms were not detected at any tested concentration, proving the expected high selectivity. Furthermore, the results showed the reusability of the sensor, as it retained the capability of detecting the specific analytes after many regeneration cycles. The use of immunosensors to detect snake venom shows important promise as an aid to snakebite treatment.
\end{abstract}

Keywords: Immunosensor; Electrochemical Impedance Spectroscopy; Polyaniline; Snake Venom

\section{Introduction}

Snake bite accidents are a major world public health problem particularly in the rural areas of non-developed countries. Distance from treatment centers, lack of transport and of a precise identification of the offending snake are contributing factors for increased mortality and sequelae [1,2] reported that snake bites accidents in Brazil are on the rise and that $70,5 \%$ were occasioned by snakes from the Bothrops genera. Currently, the administration of antivenoms is still the only approved treatment method available to the society [3] and these immunogenic solutions are often polyvalent to cover for different species of snakes of the same genera and of different genera that cohabit in a common geographical region or not. Polyvalent antivenom is a two edged sword as it provides treatment for a wide range of snake bite accidents but because of the "mosaic" and diverse nature of the venoms, they present a lower efficacy that result in the need of large quantities of extraneous proteins present in the antivenom to be injected in the patient. This large amount of proteins is a factor leading to adverse reactions associated with the treatment $[4,5]$.

In a comparative study of 102 cases of Bothrops envenoming treated with three different antivenoms, adverse reactions were observed in $17 \%$ to $25 \%$ of the treated patients, with no statistical differences between the antivenoms used [6,7]. Under 
this scenario, a precise and reliable method of diagnosis would permit the production of more specific antivenoms for instance, anti-genera serum [8]. Owing to the para specificity of antivenoms against venoms of the same genus, this approach could make available to the health system more efficacious antivenoms. These specific sera would result in the application of smaller volumes in the patient and, hence, lower frequency of adverse reactions would be expected [8-11] reported a method for the species-specific diagnosis of snake venom for the Bothrops and Lachesis genera using immunoaffinity adsorbed antibodies. That was followed by many publications showing the possibility of developing different specific methods to identify the offending snake through its venom present in body fluids of the patient $[12,13]$. These diagnostic methods are species-specific or genera specific. Enzyme-linked Immunosorbent Assays (ELISA), however precise, sensitive and reliable, have complex protocols that requires trained staff to perform, laboratory infraestructure and the results are obtained after hours of assay.

A point-of-care diagnostic system permitting the precise diagnosis of snakebites in a time frame of minutes rather than hours would greatly improve snakebite management and clinical treatment by ensuring the use of a more specific antivenom and ancillary measures to counteract the toxic effects of venoms. To meet the necessary requirements for providing a robust and precise diagnostic for snakebite envenoming, the biosensors seem to be a promising technology. Biosensors are devices that translate biological reactions into signals that can be detected and quantified. Signals can be electrical, optical or mass based [14]. In this group of biological/analytical devices, the impedimetric immunosensors have recently received particular attention since they possess a number of attractive characteristics associated with the use of electrochemical transducers. Indeed, due to these characteristics, Electrochemical Impedance Spectroscopy (EIS) based sensors are considered as promising candidates for use at on-site applications [15]. Antibody-based biosensors (immunosensor) have antibodies as the capture biomolecule and can be label free providing fast diagnostics with few steps and no need of laboratory infraestructure nor trained staff.

Antibody-based sensors can provide robust, sensitive and rapid analysis $[16,17]$. Immobilization of antibodies to the chip surface can be oriented or non-oriented. Oriented attachment results in increased sensitivity of the immunosensor and specificity $[18,19]$. The immobilization of the capture biomolecule can be made directly onto the chip surface or attached to a coating polymer with electrical conducting properties. In the last 40 years, considerable attention has been focused on conducting polymers because of their unusual electronic properties and their great potential for biomolecules immobilization [20]. Among the conductor polymers that has attracted greater industrial and scientific attention in the last few decades, polyaniline (PANI) has stood out due to its good chemical stability, easiness to prepare, low cost, precursor monomer largely available, good electrical conductivity and interesting redox properties, leading to a wide range of application possibilities in various areas [21,22]. On its basal form, PANI has its chemical formula as shown in Figure 1. Of PANI's possible applications, the use in biosensors is justified by the fact that its conductivity propitiates the efficiency of the electrical charge exchange produced by biochemical or biological reactions on the sensor's surface. As opposed to other conductive polymers, PANI presents the advantage of being biocompatible and capable to incorporate great quantities of biomolecules, resulting in better characteristics of sensibility and response time of the biosensor [23]. In this study, we prepared genera-specific antibodies that were used in the construction of biosensors for the specific detection of venoms from the Bothrops and Crotalus genera.

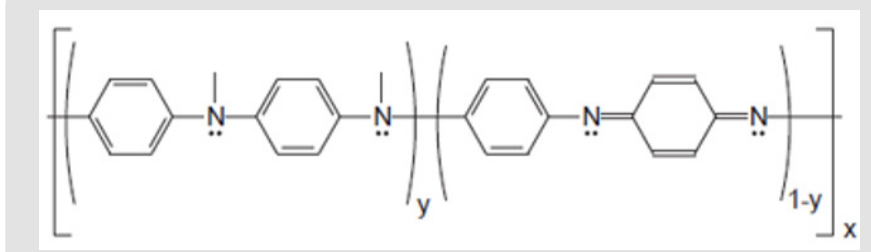

Figure 1: Chemical structure of PANI.

\section{Materials and Methods}

\section{Reagents}

Plasma from horses hyperimmunized with the venom pool containing (B. jararaca, B. jararacussu, B. alternatus, B. moojeni and $B$. neuwiedi venoms) and Crotalus durissus terrificus used for the commercial production of antibothropic and anticrotalic serum at Fundação Ezequiel Dias (FUNED) were used. Venoms from the bothropic pool and venom from Crotalus durissus terrificus and Micrurus lemniscatus snakes were kindly supplied by the Serpentarium of FUNED as lyophilized powders. Aniline from Sigma Aldrich was vacuum distilled and stored frozen under nitrogen, and stainless steel Crofer 22 APU (ThyssenKrupp VDM GmbH) as well as $25 \%$ glutaraldehyde from Sigma Aldrich were used to prepare the immunosensor.

\section{Purification and Characterization of Specific Antibodies}

Affinity purification of antibodies followed the protocol described by Heneine et al. [10] and was carried out for both anti-bothropic and anti-crotalic plasmas. Briefly, equal amounts of venoms comprising the bothropic immunizing venom pool and venom of Crotalus durissus terrificus and of Micrurus leminiscatus were insolubilized onto glutaraldehyde [24] to prepare three separate immunoadsorbents. Adsorbents were separately placed into $50 \mathrm{~mL}$ falcon tubes and volume measured. The antivenom sera were sequentially passed into the heterologous adsorbents to remove cross-reacting antibodies and finally in the homologous adsorbent to harvest the genera specific antibodies. Hyperimmunized antivenom horse plasma was diluted 1:2 in 0.01 $\mathrm{M}$ Tris- $\mathrm{HCl}$ pH 8.0 in a volume two times that of the adsorbent was 
added to the heterologous immunoadsorbent and incubated for $30 \mathrm{~min}$ at room temperature with agitation in a rotary shaker to remove cross reacting antibodies. Specific antibodies were removed from the supernatant after centrifugation at 3,000 $\mathrm{g}$ for $10 \mathrm{~min}$ at $4^{\circ} \mathrm{C}$. The immunoadsorbent was regenerated with five washing steps with $0.1 \mathrm{M}$ Tris- $\mathrm{HCl} \mathrm{pH} 8.0$ and through the addition of two adsorbent volumes of Affilit (Proteobras) eluting buffer for 15 min with agitation at room temperature and centrifugation as above. The elution process was repeated two times followed by washing steps with Tris- $\mathrm{HCl}$ until supernatant showed absorbance equal to 0.05 or lower at $280 \mathrm{~nm}$. The same aliquot of once adsorbed antiserum was adsorbed two more times.

Three times adsorbed antivenom plasma was added to the homologous adsorbent and incubated for $30 \mathrm{~min}$ with agitation at room temperature. The immunoadsorbent was then washed with Tris buffer until eluate presented optical density of 0.05 at $280 \mathrm{~nm}$ to remove unbound antibodies. The specific antibodies bound to the immunoadsorbent were eluted with three times adsorbent volume of Affilit eluting buffer and dialyzed extensively against $0.01 \mathrm{M}$ Tris-HCl pH7.4. After liophylization, the antibodies were dissolved in a volume to obtain antibody solution at $0.1 \mathrm{M}$ Tris. Antibody concentration in mg. $\mathrm{mL}^{-1}$ was calculated from absorbance at $280 \mathrm{~nm}$ divided by the exctinction coefficient of 1.36. Purity of antibody was analyzed by electrophoresis in a $10 \%$ polyacrilamide gel containing sodium dodecyl-sulphate (SDS-PAGE) [25]. Electrophoresis was performed in a Bio-Rad Protean system at a current of $35 \mathrm{~mA}$ with Tris-glycine-SDS running buffer. Samples were applied at $1.0 \mathrm{mg}$. $\mathrm{mL}^{-1}$ in volume of $10 \mathrm{~mL}$ per lane. After electrophoresis, the gel was stained in a solution of $0.2 \% \mathrm{w} / \mathrm{v}$ Comassie Blue R250 dye, $45 \%$ $\mathrm{v} / \mathrm{v}$ methanol and $10 \% \mathrm{v} / \mathrm{v}$ acetic acid, and it was destained in a solution containing $40 \% \mathrm{v} / \mathrm{v}$ methanol and $10 \% \mathrm{v} / \mathrm{v}$ acetic acid.

\section{Polyaniline Electrodeposition and Antibody Functionalization}

To obtain PANI, an aqueous solution of the precursor monomer (aniline) at $0.3 \mathrm{M}$ was prepared, containing sulphuric acid $0.3 \mathrm{M}$ as an electrolyte. Polymerization occurred on the surface of the Crofer 22 APU steel $\left(1 \mathrm{~cm}^{2}\right)$, which was previously polished with emery papers of 600, 800 and 1200 grit, through chronoamperometry. The electrodeposition was performed in a Princeton Applied Research VersaStat 3 potentiostat, applying a fix potential of 0.8 $\mathrm{V}$ vs $\mathrm{Ag} / \mathrm{AgCl}$ according to the experimental protocol described by Mohd [26]. A three-electode cell was employed with the Crofer steel as working electrode, silver/silver chloride as reference electrode and a counter electrode of platinum. After the electrodeposition, the material was rinsed with deionized water to remove the excessive monomer solution present on the substrate surface and it was dried under a light flow of nitrogen gas at room temperature. For functionalization, the substrate containing PANI as the conductive phase was immersed in an aqueous solution of $1 \% \mathrm{v} / \mathrm{v}$ glutaraldehyde for $1 \mathrm{~h}$ to promote the interaction of the aldehyde with the nitrogen cations present in the polymer. After a washing step with PBS, to remove unbound glutaraldehyde the substrate was immersed in a solution containing $10 \mu \mathrm{g}$. $\mathrm{mL}^{-1}$ of the specific antibody for 1 hour. Then, after another washing step, the substrate was immersed in a bovine serum albumin (BSA) solution at $1 \% \mathrm{w} / \mathrm{v}$ for 30 minutes to block the free binding sites of the substrate and it was, finally, newly washed with PBS. The functionalization steps are illustrated in Figure 2.

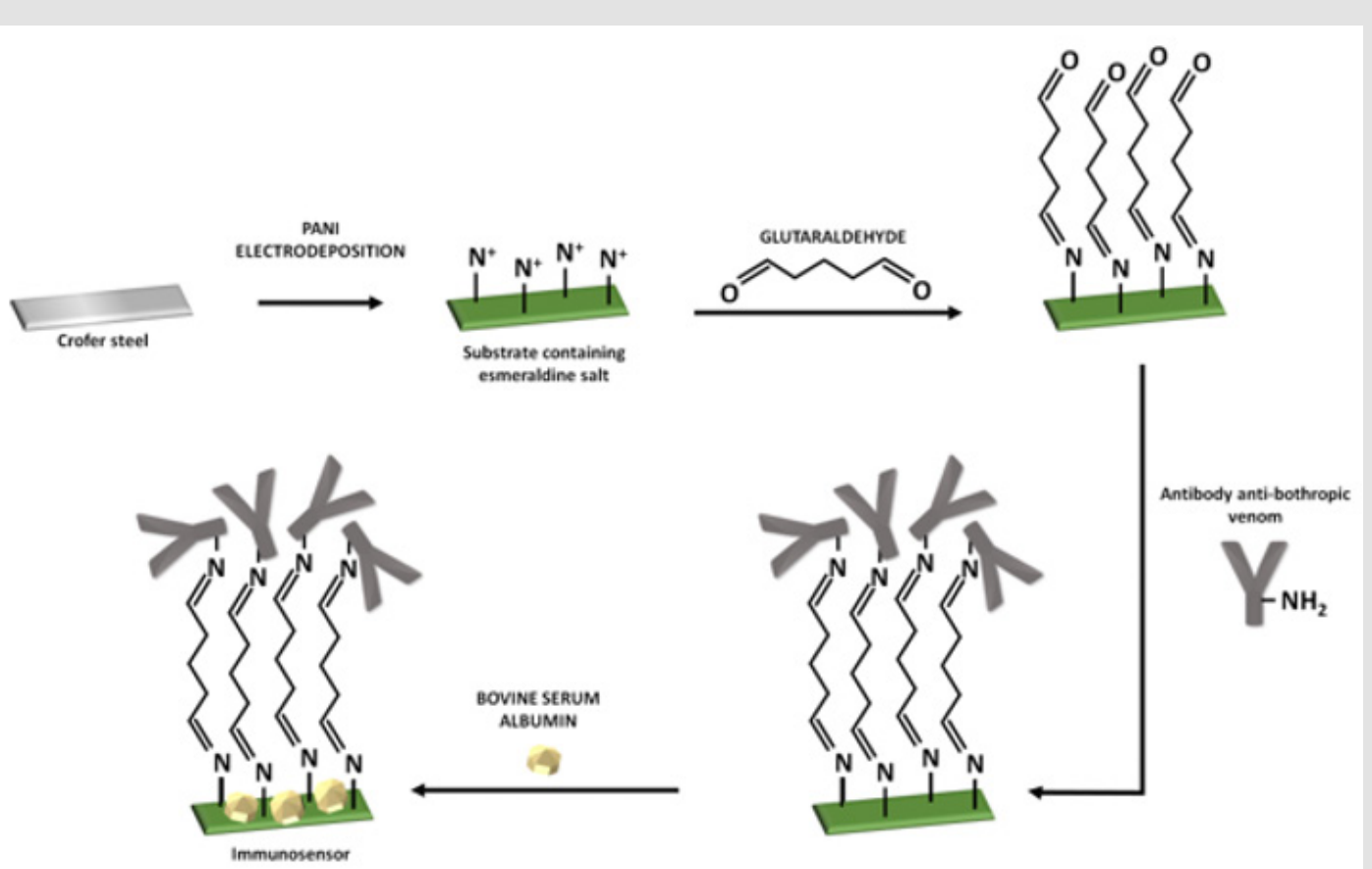

Figure 2: Functionalization steps of PANI to produce the immunosensor. 


\section{Characterization of the PANI Transducer during the} Functionalization Steps Using Cyclic Voltammetry (CV)

In order to monitor the functionalization steps to obtain the immunosensor, CV was carried out after each step of modification of the working electrode. The technique was performed in an electrolyte containing $0.01 \mathrm{M}$ Tris- $\mathrm{HCl}$ buffer containing $0.1 \mathrm{M} \mathrm{KCl}$ as supporting electrolyte. The potential was cycled from -0.4 to +0.8 $\mathrm{V}$ vs $\mathrm{Ag} / \mathrm{AgCl}$ at $50 \mathrm{mV} . \mathrm{s}^{-1}$.

\section{Sample Preparation}

Venoms were dissolved in $0.1 \mathrm{M}$ PBS pH 7.4 and centrifuged at $10,000 \mathrm{~g}$ for $30 \mathrm{~min}$. The supernatant was collected, and protein concentration measured by Bradford assay. Aliquots of each venom were separately frozen at $-20^{\circ} \mathrm{C}$ until use.

\section{EIS Measurements}

All the EIS measurements were performed using the same conventional three-electrode cell used in the PANI electrodeposition, but with the immunosensor as the working electrode containing the specific antibody attached to its surface. EIS was used to evaluate antigen-antibody interactions occurred after the exposition of the immunosensor to different analytes. The measurements were carried out in an alternating wave of $10 \mathrm{mV}$ amplitude above the Open Circuit Potencial (OCP) previously established for $300 \mathrm{~s}$. Impedance spectra were collected in a frequency range from $10^{4}$ to $10^{-2} \mathrm{~Hz}$. The electrolyte was $0.01 \mathrm{M}$ Tris- $\mathrm{HCl}$ with $0.1 \mathrm{M} \mathrm{KCl}$. The impedance data was fitted with a Randles model circuit [27]. The parameters in the equivalent circuit such as electrolyte resistance $(\mathrm{Re})$, charge transfer resistance $\left(\mathrm{R}_{\mathrm{ct}}\right)$, and a constant phase element (CPE), were determined from a fit of the model circuit to the data using the software Zview 2.9b from Scribner and Associates. All the measurements were performed in triplicate in a Faraday cage at room temperature collecting 5 points per frequency decade.

\section{Specific Venom Recognition}

The working electrode containing the specific antibodies was immersed in $2 \mathrm{~mL}$ of venom solution and incubated for $20 \mathrm{~min}$. Afterwards, the electrode was dipped in Tris buffer for $5 \mathrm{~min}$ to remove unbound samples and placed in the electrochemical cell for the impedance measurements as cited above. After the EIS test, the sensor was immersed in Afilit buffer (Proteobras, Brazil) for 5 minutes to promote the elution of antigen from the antibody and $0.01 \mathrm{M}$ Tris- $\mathrm{HCl} \mathrm{pH} 7,4$ was used to restore the immunosensor to its original condition with three immersion steps for 5 minutes each. This procedure was repeated for all venoms at various concentrations: $0.1,1,2,5$ and $10 \mu \mathrm{g} . \mathrm{mL}^{-1}$. For the working electrode containing the anti-crotalic specific antibody, the same protocol was followed. Before each data collection, a new OCP measurement was performed, aiming to ensure the immunosensor's electrochemical stability. To quantify the venoms, we assessed the parameter variation of charge transfer resistance $\left(\Delta R_{c t}\right)$, calculated as
$\Delta \mathrm{R}_{\mathrm{ct}}=\mathrm{R}_{\mathrm{ct}(\mathrm{venom})}-\mathrm{R}_{\mathrm{ct}(\text { bare)})}$, where $\mathrm{R}_{\mathrm{ct}(\mathrm{venom})}$ is the $\mathrm{R}_{\mathrm{ct}}$ value measured after adding venom at different concentrations and $\mathrm{R}_{\text {ct(bare) }}$ represents the $\mathrm{R}_{\mathrm{ct}}$ value before adding the venom. A t-Student test with a 95\% confidence level was used to compare differences between impedance readings for the different venom concentrations used and of the bare immunosensor reading (basal).

\section{Results and Discussion}

\section{Antibodies Production and Characterization}

The electrophoretic profile of the purified antibothropic antibody is shown in Figure 3. Lane A reveals a strong band at approximately $150 \mathrm{kDa}$, indicative of IgG. Lane B shows the profile of whole horse plasma containing all serum proteins. Thus, it was possible to ensure that only antivenom antibodies were collected. Similar results were obtained for the anti-Crotalus antibody.

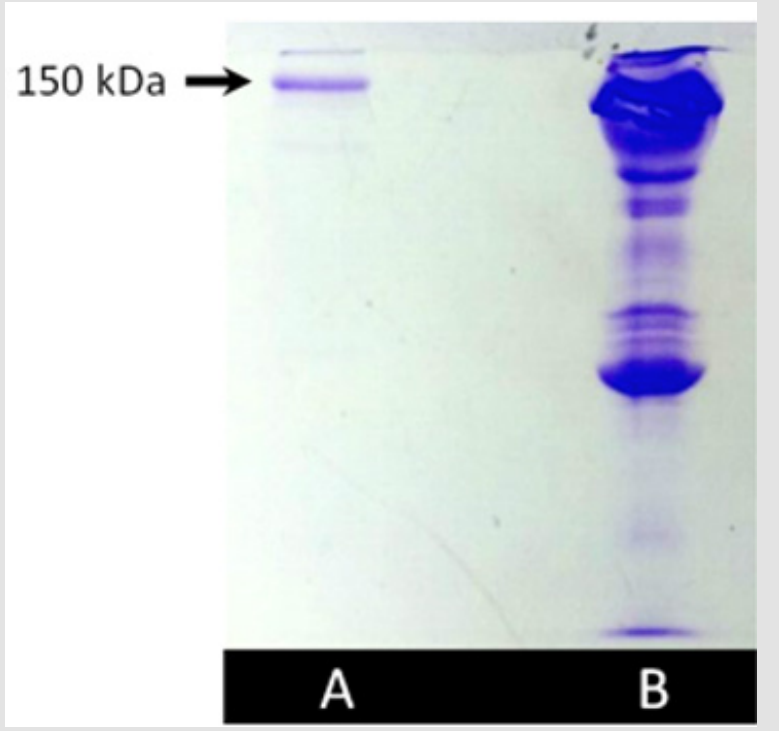

Figure 3: SDS-PAGE for (A) purified antibothropic antibody and (B) horse plasma.

\section{Electrochemical Characterization of the Immunosensor}

During the functionalization of the PANI substrate to detect the snake venoms, each step was monitored by CV. Figure 4 presents the cyclic voltammogram with respect to the changes in the current of the electrode in a potential range from -0.4 to $+0.8 \mathrm{vs} \mathrm{Ag} / \mathrm{AgCl}$ due to each functionalization step. The variations of current in each step evidenced the success of the functionalization of the electrode, confirming the possibility of using it for the target application. The anodic and cathodic currents of PANI in the electrolyte exhibited the highest values because of the structure of the polymer. PANI contains an organic chain with $\pi$ bonds, aromatic rings and free electrons that provides its high electrical conductivity [28]. In addition, Virji et al. [29] pointed out the mobility of polarons through the polymer backbone as an important contributor to the PANI conductivity. After modifying the PANI coating with glutaraldehyde, antibodies and BSA, the current suffered subsequent decreases in 
its value because of the insulator features of these molecules, which hinders the process of electron/charge transfer of the substrate. In the last step, after incubating the substrate with BSA, the overall current significantly decreased, which indicates that the proteins were successfully attached to the surface. This result is especially important because suggests the impossibility of cross-linking reactions between free electro active areas of the immunosensor and heterologous venoms, since the blocking step caused the formation of a protective layer in the sensor [30]. Accordingly, the possibility for immunological reactions could only be the interaction with the attached antibodies, enhancing the immunosensor selectivity. With glutaraldehyde, antibothropic antibodies and BSA

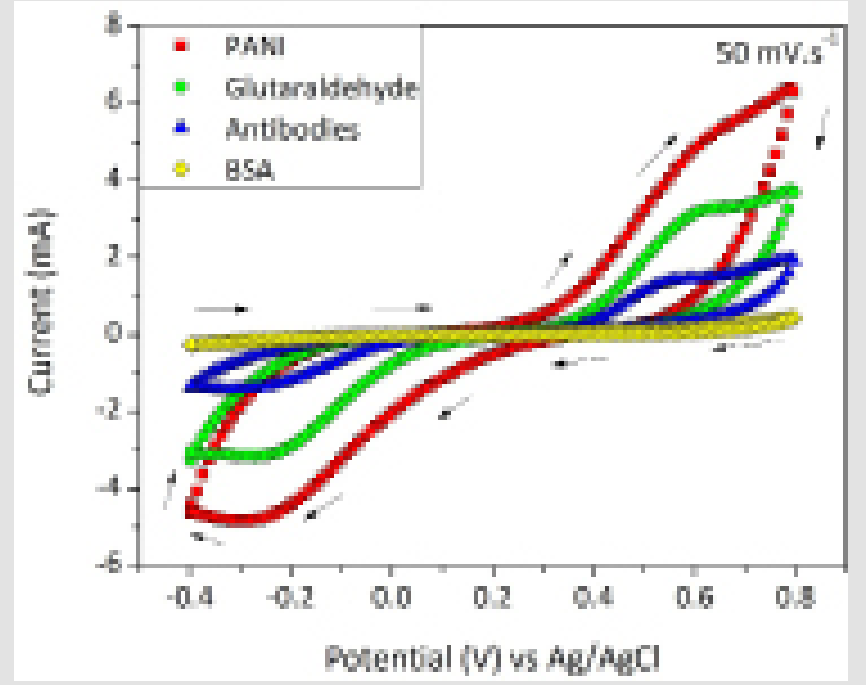

Figure 4: Cyclic voltammogram of the transducer substrate coated with PANI and modified with glutaraldehyde, antibothropic antibodies and BSA.

\section{Impedimetric Recognition of the Venom Analyte}

In Figure 5, the Bode diagram shows the good correspondence between the experimental and fitted curve indicating that the Randle model is representative of the phsysical interface phenomenoms between the electrodes and the electrolyte. Insert represents the equivalent circuit adopted to fit the impedance data, where Re is the electrolyte resistance; Rct is the charge transfer resistance and CPE the constant phase element. Besides, the fit quality was also ensured considering the chi-squared $\left(\chi^{2}\right)$ parameter, which was lower than $10^{-3}$ independent of the venom concentration or of testing the bare device. The criterion of $\chi^{2}<10^{-3}$ indicates that the chosen equivalent circuit well represents the experimental data and, then, the values of the electrical elements can be employed to interpret the electrochemical phenomena taking place at the interfaces of the sensor and the surrounding electrolyte [31,32]. Figure 6 shows a representative Nyquist diagram obtained for the bothropic immunosensor exposed to the homologous venom of Bothrops in concentrations of $0.1,1,2,5$ and $10 \mu \mathrm{g} . \mathrm{mL}^{-1}$. The result shows a correlation between higher venom concentrations and increased $R_{c t}$ values. This behavior occurs because antibodies form immunocomplexes when they bind to the analyte, blocking electrically the sensor surface.

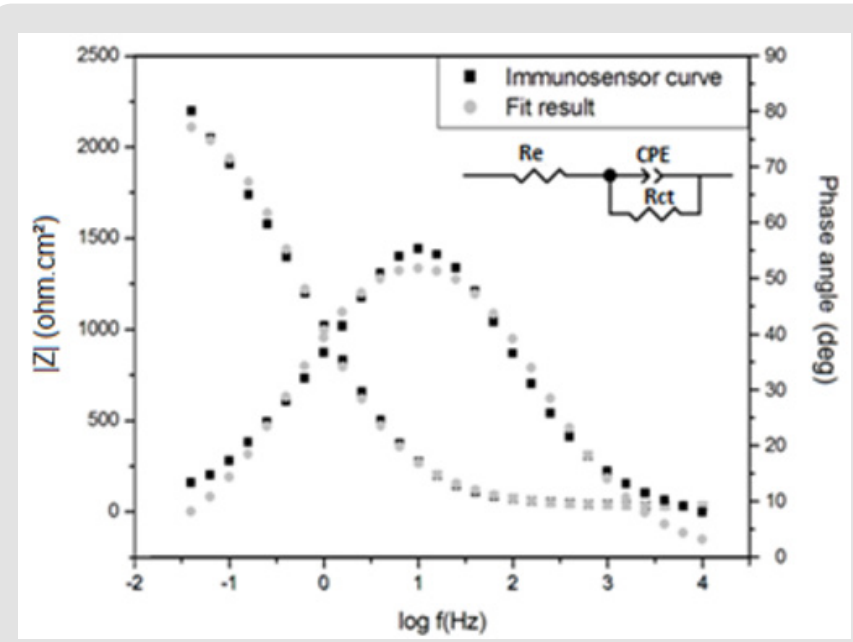

Figure 5: Bode Diagram and equivalent circuit fitted for the impedance spectra of the PANI immunosensor.

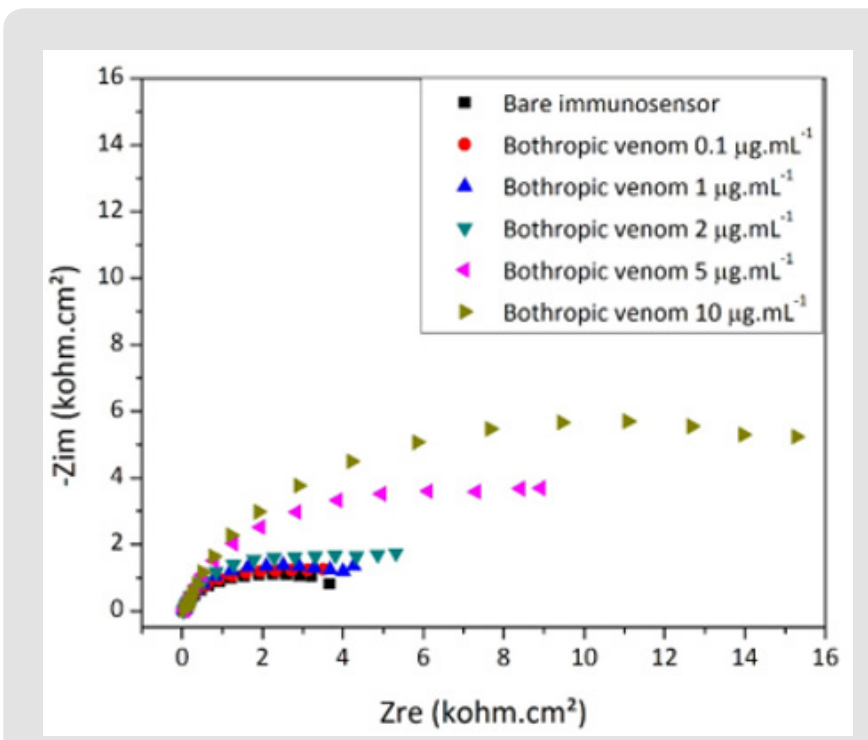

Figure 6: Nyquist plots of the biosensor developed to detect venom from Bothrops snakes at various concentrations.

Thus, greater amounts of antigen-antibody complex increase the resistance of the sensor to transfer charge with the environment. The graphic in Figure 7 shows the fitted results for the analysis with the bothropic, crotalic and elapidic venoms with the bothropic immunosensor. The specificity of the sensor is evident at all tested venom concentrations. Figure 7 shows the strong linear correlation between venom concentration and increase in $\Delta \mathrm{R}_{\mathrm{ct}}$ values for the bothropic venom obtained from the average of three experiments. The higher was the bothropic venom concentration ( $\mathrm{Vb}$ ), the higher was the consequent analytical signal. The value of the coefficient of linear regression $\left(\mathrm{R}^{2}\right)$ close to 1.00 corroborates the linearity of the sensor, which is expressed in Eq. 1.

$$
\Delta R_{c t}=1.61 V_{b}+0.16
$$



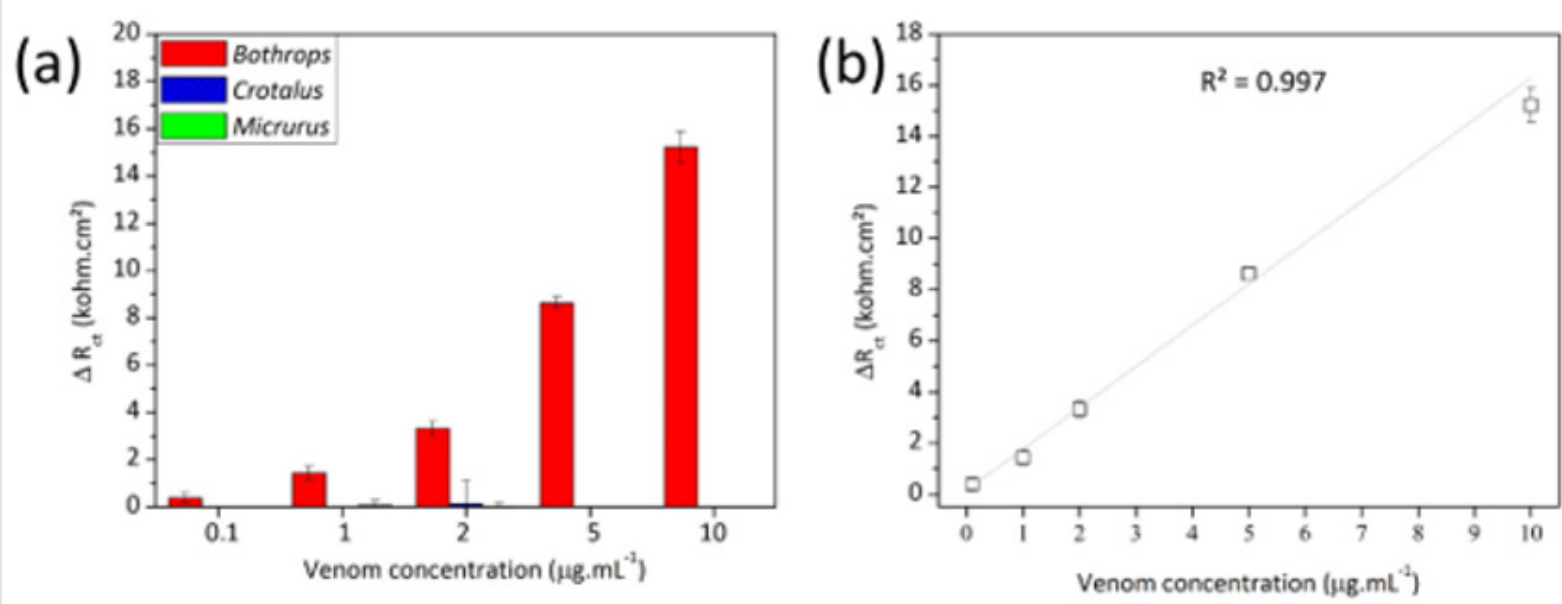

Figure 7: Variation of $\mathrm{R}_{\mathrm{ct}}$ due to the exposition of the PANI-based immunosensor to the homologous bothropic venom and heterologous crotalic and elapidic venom from 0.1 to $10 \mu \mathrm{g} \cdot \mathrm{mL}^{-1}$ (a) and linearity of the analytical response towards the venom of Bothrops (b).

\section{Crotalic Venom Detection}

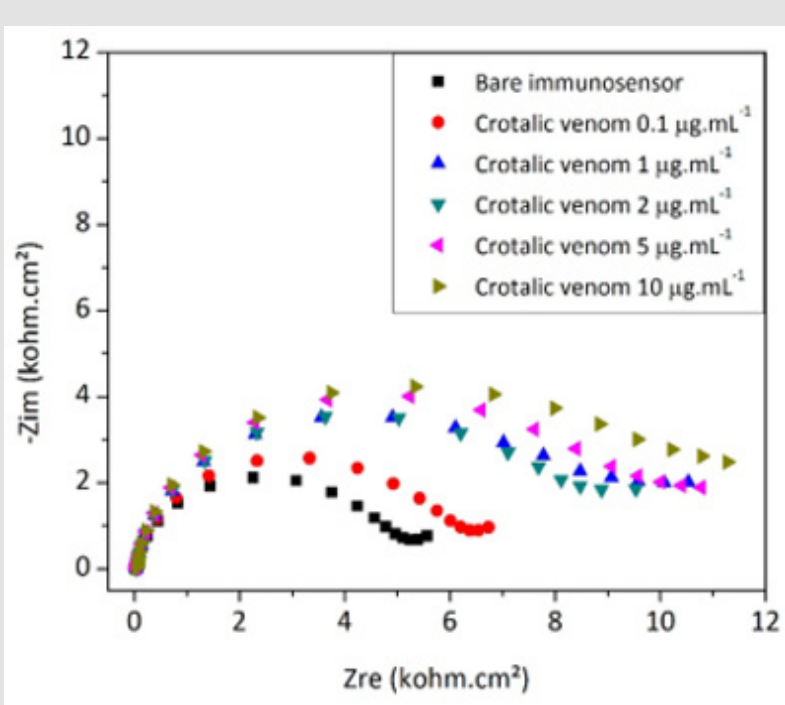

Figure 8: Nyquist plots of the biosensor developed to detect venom from Crotalus snakes at various concentrations.

Figure 8 shows a representative Nyquist diagram obtained for the crotalic immunosensor exposed to the homologous venom of Crotalus at concentrations of $0.1,1,2,5$ e $10 \mu \mathrm{g} . \mathrm{mL}^{-1}$. The increase of the capacitive arc when the device was reacted to crotalic venom corroborates the formation of the immunocomplex, which electrically blocks the sensor surface. The graphic in Figure 9 the graph shows the fitted results for the analysis with the crotalic, bothropic and elapidic venoms with the crotalic immunosensor. The specificity of the sensor is evident at all tested venom concentrations. Figure 9 shows a good linear correlation between venom concentration and increase in $R_{c t}$ values for the crotalic venom obtained from the average of three experiments. Probably due to the saturation of the free antibodies at the top of functionalized PANI, the immunosensor response was modeled to a polynomial equation (Eq. 2), which considers the plateau at the higher concentrations. In this equation, "V" is the concentration of crotalic venom.

$$
\Delta R_{c t}=1.95+0.88 \ln \left(V_{c}+0.27\right)
$$

\section{Statistical Analyisis}

Taking in account the response of the immunosensor towards the homologous bothropic venom at the different tested concentrations, there was a statistical difference between all $\mathrm{R}_{\mathrm{ct}(\text { venom) }}$ values and the basal response $\left(\mathrm{R}_{\mathrm{ct}(\mathrm{bare})}\right)$. On the other hand, the impedance readings concerning the heterologous venoms did not demonstrate significant differences even at the highest concentrations. Regarding the device for recognition of venom from Crotalus snakes, the results were similar except for the concentration of $1 \mu \mathrm{g}$. $\mathrm{mL}^{-1}$, at which the venom from Bothrops was positive albeit lower than for the homologous venom reading, therefore rejecting the null hypothesis of statistical similarity.

\section{Discussion}

In countries where snakebite accidents are frequent and still a major health problem, accurate and rapid point-of-care diagnostic tests are urgently needed. Nowadays, especially in rural areas, the diagnostic still relies on the visual identification of the snake, which is not always possible, and on clinical signs of the envenomation [4]. To address the problem, we have focused on the development of a methodology to produce immunosensors capable of selectively detecting snake venoms in few minutes by the simple addition of the sample to the device. Herein, the presented data strongly indicated that the immunosensors could well discriminate venoms from snakes of the Bothrops genus when tested against venoms from the Crotalus and Micrurus genera (Figure 7) and venoms from Crotalus gerera when tested against venoms from Bothrops and Micrurus snakes (Figure 9). When in contact with the homologous venom solution, the probe antibodies recognize the proteins of 
the venom and form an immunological antigen-antibody complex. Because of the insulate properties of both biological molecules and the consequent steric effect of the formed protein layer, the immunocomplex hinders the charge transfer processes that previously took place in the PANI backbone and increase the global $\mathrm{R}_{\mathrm{ct}}$ of the sensor $[30,33]$.
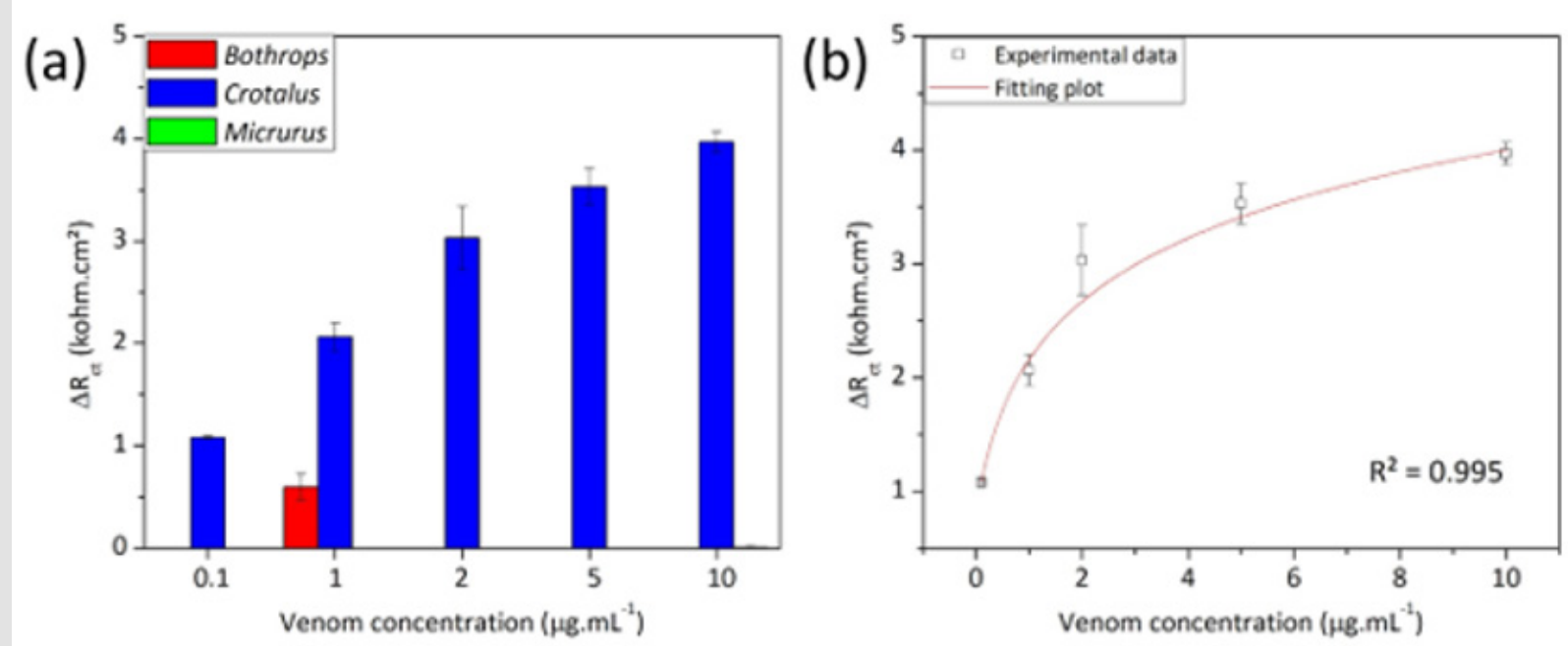

Figure 9: Variation of $R_{c t}$ due to the exposition of the PANI-based immunosensor to the homologous crotalic venom and heterologous bothropic and elapidic venom from 0.1 to $10 \mu \mathrm{g} \cdot \mathrm{mL}^{-1}$ (a) and linearity of the analytical response towards the venom of Crotalus (b).

Affinity purification of commercial antibodies for the diagnostic assays of snakebite accidents has been employed, albeit in ELISA strips, with similar results as obtained by us, regarding specificity $[34,35]$. The degree of purification of the antivenom antibodies was sufficient for application as capture biomolecule in the immunosensor as it was capable to detect the homologous venoms in a range of concentrations varying from 0.1 to $10 \mu \mathrm{g} \cdot \mathrm{mL}^{-1}$. Antibody attachment was non-oriented and could explain the lower limit of detection of only $0.1 \mu \mathrm{g} \cdot \mathrm{mL}^{-1}$ at the incubation time used. Nonetheless specificity was not affected as only the homologous venoms were detected across the concentration range tested. Detection limits reported in the literature for immunoassays are mostly in nanogram level and even pictogram [12]. Actual detection of bothropic venom in serum of patients has been reported to be in the range of 13 ng.m L $\mathrm{L}^{-1}$ to 120 ng.m L ${ }^{-1}$ [36]. Another report quantifying venom in the serum of patients in Peru, which included snakes from the botropic genera, showed the detected venom levels to be in the range of 3 ng.m L ${ }^{-1}$ to 466 ng.m L ${ }^{-1}$ [4].

Oriented attachment or increased incubation time could have resulted in lower limit of detection without specificity loss [37]. All crotalic venoms included in the venom pool for the production of the antiserum were crotamine positive therefore our test would account for the geographical venom composition variations identifying crotamine positive and negative crotalic venoms, and crotoxin, the main lethal component of Crotalus durissus venoms, present in all specimens of the genus. The high linearity of the analytical response observed for the specific identification of both bothropic and crotalic venoms corroborated the capability of the immunosensors to discriminate venom concentrations, also confirming its robustness as the same sensors were regenerated and reused several times.

\section{Conclusion}

The immunoaffinity purified (anti-Bothrops and anti-Crotalus) antibodies were suitable as capture biomolecule for the application of electrochemical impedance spectroscopy as transduction technique. The functionalization of PANI was monitored by CV. This technique confirmed that the pure and selective antibodies were successfully attached to the sensor electrode, causing successive decreases of the overall current due to the insulator characteristic of the used molecules. The higher variations of $R_{c t}$ were observed at the highest concentrations of homologous venoms, indicating that the device was sensitive to the presence of the target analyte. Instead, the contact of the immunosensors with heterologous venoms did not significantly change this parameter. Diagnosis of snakebite should primarily identify the venom presence or absence, and as such the immunosensors developed by us could be used in the specific diagnosis of bothropic and crotalic snakebite accidents.

\section{Acknowledgements}

The authors of this work acknowledge Fundação de Amparo à Pesquisa do Estado de Minas Gerais (FAPEMIG), Coordenação de Aperfeiçoamento de Pessoal de Nível Superior (CAPES) and Fundação Ezequiel Dias (FUNED) for supporting this research. Rômulo Righi for providing the snake venoms. 


\section{References}

1. Harrison RA, Gutiérrez JM (2016) Priority Actions and Progress to Substantially and Sustainably Reduce the Mortality, Morbidity and Socioeconomic Burden of Tropical Snakebite. Toxins 8(12): 351.

2. Bochner R, Fiszon JT, Machado C (2014) A profile of snake bites in Brazil, 2001 to 2012. Journal of Clinical Toxicology 4:3.

3. (2015) World Health Organization, WHO. Snake Antivenom Immunoglobulins.

4. Theakston RDG, Laing GD (2014) Diagnosis of snakebite and the importance of immunological tests in venom research. Toxins 6(5): 1667-1695.

5. Ratanabanangkoon K (2003) Merit and demerit of polyvalent snake antivenoms. Journal of Toxicology 22(1): 77-89.

6. Silva IM, Tavares AM (2012) Comparative evaluation of adverse effects in the use of powder trivalent antivenom and liquid antivenoms in Bothrops snake bites. Revista da Sociedade Brasileira de Medicina Tropical 45(4): 523-525

7. Sousa LF, Nicolau CA, Peixoto PS, Bernardoni JL, Oliveira SS, et al. (2013) Comparison of phylogeny, venom composition and neutralization by antivenom in diverse species of Bothrops complex. Plos Neglected Tropical Diseases 7: 9.

8. Jorge RJB, Monteiro HSA, Gonçalves Machado L, Guarnieri MC, Ximenes RM, et al. (2015) Venomics and antivenomics of Bothrops erythromelas from five geographic populations within the Caatinga ecoregion of northeastern Brazil. Journal of Proteomics 114: 93-114.

9. Pardal PPO, Pardal JSO, Gadelha MAC, Rodrigues LS, Feitosa DT, et al. (2010) Envenomation by Micrurus coral snakes in the Brazilian Amazon region: report of two cases. Rev Inst Med Trop S Paulo 52(6): 1678-9946.

10. Heneine LGD, Catty D (1990) Development of a species-specific ELISA for Brazilian pit-viper venoms. Brazilian J Med Biol Res. 23(6): 585-588.

11. Heneine LGD, Catty D (1993) Species-specific detection of venom antigens from snakes of the Bothrops and Lachesis genera. Toxicon 31(5): 591-603.

12. Heneine LGD, Santos MRA, Carvalho AJD, Gontijo SS (1999) A Capture Enzyme-Linked Immunosorbent Assay for Species-Specific Detection of Bothrops Venoms. Journal of Immunoassay 20(1-2): 91-101.

13. Dhananjaya BL, Menon JC, Joseph JK, Raveendran DK, Oommen OV, et al (2015) Snake venom detection kit (SVDK): update on current aspects and challenges. Clinical Toxinology in Asia Pacific and Africa (2): 379400 .

14. International Union of Pure and Applied Chemistry, IUPAC (1999) Eletrochemical Biosensors: recommended definitions and classification. Technical report. Pure Applied Chemistry 71(12): 2333-2348.

15. Prodromidis MI (2009) Impedimetric immunosensors - a review. Electrochimica Acta 55(14): 4227-4233.

16. Byrne B, Stack E, Gilmartin N, O Kennedy R (2009) Antibody-based sensors: principles, problems and potential for detection of pathogens and associated toxins. Sensors 9: 4407-4445.

17. Sharma S, Byrne H, O Kennedy JO (2016) Antibodies and antibodyderived analytical biosensors. Essays in Biochemistry 60(1): 9-18.

18. Tajima N, Takai M, Ishihara K (2011) Significance of antibody orientation unraveled: well-oriented antibodies recorded high binding affinity. Anal Chem 83(6): 1969-1976.

19. Trilling AK, Beekwilder J, Zuilhof H (2013) Antibody orientation on biosensor surfaces: a minireview. Analyst 138: 1619-1627.
20. Ouerghi O, Touhnami A, Jaffrezic Renault N, Martelet C, Ouada HB, et al. (2002) Impedimetric immunosensor using avidin-biotin for antibody immobilization. Bioelectrochemistry 56(1): 131-133.

21. Sai VVR, Mahajan S, Contractor AQ Mukherji S (2006) Immobilization of antibodies on polyaniline films and its application in a piezoelectric immunosensor. Anal Chem 78: 8368-8373.

22. Oueiny C, Berlioz S, Perrin, F, Carbon nanotube-polyaniline composites (2014) Progress in Polymer Science 39(4): 707-748.

23. Prince S (2015) Characterization of electrodeposited polyaniline biosensor platform for Escherichia coli 0157:H7 detection. Master's report, Michigan Technological University.

24. Avrameas S, Ternynck T (1969) The cross-linking of proteins with glutaraldehyde and its use for the preparation of immunoadsorbents. Immunochemistry Pergamon Press 6: 53-66.

25. Laemmly UK (1970) Cleavage of structural proteins during the assembly of the head of Bacteriophage T4. Nature 227: 680-685.

26. Mohd Y, Ibrahim R, Zainal MF (2012) Electrodeposition and characterization of polyaniline films. IEEE Symposium on Humanities, Science and Engineering Research.

27. Katz E, Willner I (2003) Probing biomolecular interactions at conductive and semiconductive surfaces by Impedance Spectroscopy: routes to impedimetric immunosensors, DNA-sensors, and enzyme biosensors. Electroanalysis 15(11).

28. Faria RAD, Iden H, Bharucha E, Lins VFC, Messaddeq Y, et al. (2018) A new tool for the detection of horsemeat adulteration in raw meat. Journal of Biosensors \& Bielectronics 9(4): 264.

29.Virji S, Huang J, Kaner RB, Weiller H (2004) Polyaniline nanofiber gas sensors: examination of response mechanisms. Nano Letters 4(3): 491496.

30. Faria RAD, Lins VFC, Nappi GU, Matencio T, Heneine LGD, et al. (2018) Development of an impedimetric immunosensor for specific detection of snake venom. BioNanoScience 8: 988-996.

31. Faria RAD, Iden H, Heneine LGD, Matencio T, Messaddeq Y, et al. (2019) Non-enzymatic impedimetric sensor based on 3-aminophenylboronic acid functionalized screen-printed carbon electrode for highly sensitive glucose detection. Sensors 19: 1686.

32. Faria RAD, Heneine LGD, Lins VFC, Matencio T (2019) AISI 304 satinless steel as a transducer substrate in electrochemical biosensors for medical applications. Biomedical Journal of Scientific \& Technical Research 18: 13382-13388

33. Faria RAD, Heneine LGD, Matencio T, Messaddeq Y (2019) Faradaic and non-faradaic electrochemical impedance spectroscopy as transduction techniques for sensing applications. International Journal of Biosensors \& Bioelectronics 5: 1-3.

34.Dong LV, Eng KH, Quyen LK, Gopala krishnakone P (2004) Optical immunoassay for snake venom detection. Biosensors and Bioelectronics 19: $1285-1294$

35. Gao J, Wang J, Qu Y, Ma X, Ji X, et al. (2013) Immunoreactivity between venoms and commercial antiserums in four chinese snakes and venom identification by species-specific antibody. Journal of Immunological Methods 387(1): 211-218.

36. Barral Netto A, Schriefer A, Barral ARP, Almeida A Mangabeira (1991) Serum Levels of Bothropic Venom in Patients without Antivenom Intervention. The American Journal of Tropical Medicine and Hygiene 45(6): 751-754

37. Gunnar, Carl Fredrik Mandenius (2011) Sensors and Actuators, B. Chemical 158(1): 265-270. 
ISSN: 2574-1241

DOI: 10.26717/BJSTR.2020.25.004190

Ricardo Adriano Dorledo de Faria. Biomed J Sci \& Tech Res

(c) This work is licensed under Creative

Submission Link: https://biomedres.us/submit-manuscript.php

BIOMEDICAL
RESEARCHES $\quad \begin{aligned} & \text { Assets of Publishing with us } \\ & \text { - Global archiving of articles }\end{aligned}$

